\title{
Molecular Detection of Soil-Transmitted Helminths and Enteric Protozoa Infection in Children and Its Association with Household Water and Sanitation in Manhiça District, Southern Mozambique
}

\author{
Berta Grau-Pujol 1,2,3,*(D), Inocencia Cuamba ${ }^{2}$, Chenjerai Jairoce ${ }^{2}$, Anelsio Cossa ${ }^{2}$, Juliana Da Silva ${ }^{4}$, \\ Charfudin Sacoor ${ }^{2}$, Carlota Dobaño ${ }^{1}$, Augusto Nhabomba ${ }^{2}$, Rojelio Mejia ${ }^{5,+}$ and Jose Muñoz ${ }^{1,+}$ \\ 1 Barcelona Institute for Global Health (ISGlobal), Hospital Clínic-University of Barcelona, \\ 08036 Barcelona, Spain; carlota.dobano@isglobal.org (C.D.); jose.munoz@isglobal.org (J.M.) \\ 2 Centro de Investigação em Saúde de Manhiça (CISM), Maputo 1929, Mozambique; \\ inocencia.Cuamba@manhica.net (I.C.); chenjerai.Jairoce@manhica.net (C.J.); anelsio.cossa@manhica.net (A.C.); \\ charfudin.Sacoor@manhica.net (C.S.); augusto.nhabomba@gmail.com (A.N.) \\ 3 Mundo Sano Foundation, Buenos Aires 1535, Argentina \\ 4 Department of Medicine, Baylor College of Medicine, Houston, TX 77030, USA; 1xi7@cdc.gov \\ 5 Department of Pediatrics, National School of Tropical Medicine, Baylor College of Medicine, \\ Houston, TX 77030, USA; Rojelio.Mejia@bcm.edu \\ check for \\ updates \\ * Correspondence: berta.grau@isglobal.org; Tel.: +34-9322-75400 \\ + Contributed equally to this work and share last authorship.
}

Citation: Grau-Pujol, B.; Cuamba, I.; Jairoce, C.; Cossa, A.; Da Silva, J.; Sacoor, C.; Dobaño, C.; Nhabomba, A.; Mejia, R.; Muñoz, J. Molecular Detection of Soil-Transmitted Helminths and Enteric Protozoa Infection in Children and Its Association with Household Water and Sanitation in Manhiça District, Southern Mozambique. Pathogens 2021, 10, 838. https://doi.org/ $10.3390 /$ pathogens10070838

Academic Editor: Geoff Hide

Received: 21 May 2021

Accepted: 30 June 2021

Published: 3 July 2021

Publisher's Note: MDPI stays neutral with regard to jurisdictional claims in published maps and institutional affiliations.

Copyright: () 2021 by the authors. Licensee MDPI, Basel, Switzerland. This article is an open access article distributed under the terms and conditions of the Creative Commons Attribution (CC BY) license (https:// creativecommons.org/licenses/by/ $4.0 /)$.
Abstract: Intestinal parasite infections can have detrimental health consequences in children. In Mozambique, soil-transmitted helminth (STH) infections are controlled through mass drug administration since 2011, but no specific control program exists for enteric protozoa. This study evaluates STH and protozoan infections in children attending healthcare in Manhiça district, Southern Mozambique, and its association with water and sanitation conditions. We conducted a cross-sectional study in children between 2 and 10 years old in two health centers $(n=405)$. A stool sample and metadata were collected from each child. Samples were analyzed by multi-parallel real-time quantitative PCR (qPCR). We fitted logistic regression-adjusted models to assess the association between STH or protozoan infection with household water and sanitation use. Nineteen percent were infected with at least one STH and 77.5\% with at least one enteric protozoon. qPCR detected $18.8 \%$ of participants with intestinal polyparasitism. Protected or unprotected water well use showed a higher risk for at least one protozoan infection in children (OR: 2.59, CI: 1.01-6.65, $p$-value = 0.010; OR: 5.21, CI: $1.56-17.46, p$-value $=0.010$, respectively) compared to household piped water. A high proportion of children had enteric protozoan infections. Well consumable water displayed high risk for that.

Keywords: Mozambique; protozoa; soil-transmitted helminths; Giardia; sub-Saharan Africa; intestinal parasites; PCR; water; sanitation; poverty

\section{Introduction}

Intestinal parasites are transmitted by the fecal-oral route or by skin penetration. Thus, they mostly affect deprived populations, and specifically children, with lack of hygiene, safe water, and improved sanitation access. Their infections can be asymptomatic or cause abdominal pain, diarrhea, malnutrition, anemia, and impaired development and growth [1-3].

Soil-transmitted helminths (STH) are intestinal parasites that affect approximately 1.5 billion people worldwide [2]. The World Health Organization (WHO) formally consider STH as roundworm (Ascaris lumbricoides), whipworm (Trichuris trichiura), and hookworm (Necator americanus and Ancylostoma duodenale). WHO set the goal to reduce moderate and high intensity STH infections to less than $2 \%$ in $96 \%$ of endemic countries by 2030 [4]. For 
that, the main STH control strategy is mass drug administration (MDA) with albendazole or mebendazole to populations at risk once a year if prevalence is over $20 \%$ and twice a year if it is over $50 \%$. MDA-continued campaigns have substantially reduced STH infections in many countries [5-7]. Due to ongoing transmission, the WHO recommends improving water, sanitation, and hygiene (WASH) strategies to reduce STH reinfection, but it has been poorly accomplished [8].

Other intestinal parasites are not targeted by a specific control program neither can benefit from STH MDA [9]. Strongyloides stercoralis or enteric protozoa such as Giardia lamblia, Entamoeba histolytica, and Cryptosporidium spp are examples of those [10]. Indeed, global distribution and burden for these four parasites have been unrepresented for many years. For S. stercoralis, two recent studies estimated their burden (386 million people infected) [11,12]. Regarding enteric protozoa, the estimated global burden in 2010 was almost 3 million Disability Adjusted Life Years (DALYs) [13]. Nevertheless, they are estimations in response to missing regional and national data. Moreover, most surveillance studies have not used sensitive molecular diagnostic techniques [14,15].

Mozambique is a country in sub-Saharan Africa where $72 \%$ of the population have access to safe water and only 39\% utilized improved sanitation in 2015 [16]. Occasional studies have reported STH and S. stercoralis infections in Mozambique for decades [17], but current published data are scarce. Concerning enteric pathogens, although they were described in children under $5[18,19]$, a small number of studies examined enteric protozoa infections in those over 5 years old in Mozambique [20,21].

In this study, we aim to describe STH and enteric protozoa infection prevalence in children between 2 and 10 years old attending healthcare in Manhiça District, Southern Mozambique, using a highly sensitive diagnostic technique, multi-parallel real-time quantitative PCR (qPCR). In addition, we assessed the association between STH and protozoan infections with household's water and sanitation facilities used.

\section{Results}

\subsection{Participant's Characteristics}

We recruited 405 children, 232 from Manhiça-sede and 173 from Ilha Josina health centers. Half (51.6\%) were male and 52.1\% were between 2 and 5 years old. The proportion of participants belonging to a poor socioeconomical status was $24.2 \%, 12.1 \%$ in Manhiçasede, and $40.5 \%$ in Ilha Josina. Regarding household water source facilities, $46.4 \%$ of study participants were living in a household with piped water $(76.3 \%$ in Manhiça-sede and $6.3 \%$ in Ilha Josina) and $17.3 \%$ were living in a household using unprotected well (3.4\% in Manhiça-sede and $35.8 \%$ in Ilha Josina). Regarding household sanitation facilities, $63 \%$ of participants were living in a household using an improved latrine (51.7\% in Manhiça-sede and $78 \%$ in Ilha Josina), followed by $15.3 \%$ who were using unimproved latrine $(22.4 \%$ in Manhiça-sede and $5.8 \%$ in Ilha Josina), and $12.1 \%$ who were using a toilet connected to a septic tank (20.7\% in Manhiça-sede and $0.6 \%$ in Ilha Josina). Six percent of participants did not have a latrine at home, 3.4\% in Manhiça-sede and 9.8\% in Ilha Josina. Eighteen participants were HIV positive (Table 1 ).

\subsection{STH and Protozoan Infections}

Almost a fifth of participants (19.3\%) were infected with at least one STH (including S. stercoralis) detected by multiparallel qPCR, $22.8 \%$ of participants in Manhiça-sede, and $14.5 \%$ in Ilha Josina (Figure 1). S. stercoralis (8.6\%) and A. lumbricoides (7.4\%) were the most frequently detected, followed by T. trichiura (4\%), N. americanus (3\%), and A. duodenale $(0.5 \%)$ (Table 2$)$. A higher proportion of STH infected were observed in children older than 5 years old $(24.7 \%)$ compared to $2-5$ years old group $(14.2 \%, p$-value $=0.008)$. We did not observe any difference in the proportion of STH-infected children between HIV infected or not $(16.7 \%$ and $19.5 \%$, respectively, $p$-value $=1.000)$. 
Table 1. Participants sex, age, household socioeconomical status and main water and sanitation facility used per recruitment health center and in total.

\begin{tabular}{cccc}
\hline Characteristics & Manhiça-Sede (\%) & Ilha Josina (\%) & Total (\%) \\
Sex & & & \\
Female & $109(47.0)$ & $87(50.3)$ & $196(48.4)$ \\
Male & $123(53.0)$ & $86(49.7)$ & $209(51.6)$ \\
Age & & & \\
2-5 years old & $134(57.8)$ & $77(44.5)$ & $211(52.1)$ \\
6-10 years old & $98(42.2)$ & $96(55.5)$ & $194(47.9)$ \\
Rich & & & \\
Middle-class & $113(48.7)$ & $26(15.0)$ & $139(34.3)$ \\
Poor & $57(24.6)$ & $45(26.0)$ & $102(25.2)$ \\
Missing & $28(12.1)$ & $70(40.5)$ & $98(24.2)$ \\
Water source & $34(14.7)$ & $32(18.5)$ & $66(16.3)$ \\
Piped water inside the household & $56(24.1)$ & & \\
Piped water outside the household & $121(52.2)$ & $7(2.3)$ & $60(14.8)$ \\
Fountain & $17(7.3)$ & $5(4.0)$ & $128(31.6)$ \\
Protected well & $7(3.0)$ & $83(48.0)$ & $22(5.4)$ \\
Unprotected well & $8(3.4)$ & $62(35.8)$ & $70(22.2)$ \\
Other & $8(3.4)$ & $0(0.0)$ & $8(2.0)$ \\
Missing & $15(6.5)$ & $12(6.9)$ & $27(6.7)$ \\
Sanitation facility & & & \\
Improved latrine & $48(20.7)$ & $1(0.6)$ & $49(12.1)$ \\
Unimproved latrine & $120(51.7)$ & $135(78.0)$ & $255(63.0)$ \\
Without latrine & $52(22.4)$ & $10(5.8)$ & $62(15.3)$ \\
Missing & $8(3.4)$ & $17(9.8)$ & $25(6.2)$ \\
HIV infection & $4(1.7)$ & $10(5.8)$ & $14(3.5)$ \\
Positive & $15(6.5)$ & $3(1.7)$ & $18(4.4)$ \\
Negative & $0(0.0)$ & $215(124.3)$ & $385(95.1)$ \\
Missing & & $2(1.2)$ & $2(0.5)$ \\
\hline & & &
\end{tabular}

Table 2. Number and percentage (\%) of participants with a soil-transmitted helminth (STH) infection, including Strongyloides stercoralis, or enteric protozoan infections.

\begin{tabular}{cc}
\hline Intestinal Parasite & Total \\
& Multi-Parallel qPCR (\%) \\
\hline Soil-transmitted helminths & \\
Ascaris lumbricoides & $30(7.4)^{\mathrm{a}}$ \\
Trichuris trichiura & $16(4.0)^{\mathrm{b}}$ \\
Necator americanus & $12(3.0)^{\mathrm{a}}$ \\
Ancylostoma duodenale & $2(0.5)^{\mathrm{a}}$ \\
Strongyloides stercoralis & $35(8.6)^{\mathrm{a}}$ \\
\hline At least one STH & $78(19.3)^{\mathrm{a}}$ \\
\hline Enteric protozoa & \\
Giardia lamblia & $313(77.3)^{\mathrm{a}}$ \\
Entamoeba histolytica & $3(0.7)^{\mathrm{a}}$ \\
Cryptosporidium parvum/hominis & $9(5.7)^{\mathrm{c}}$ \\
\hline At least one enteric protozoan & $314(77.5)^{\mathrm{a}}$ \\
\hline
\end{tabular}

a Total participants analyzed: $n=405 ;{ }^{b}$ total participants analyzed: $n=397 ;{ }^{c}$ total participants analyzed: $n=157$.

Regarding protozoa, $77.5 \%$ of participants were infected by at least one enteric species, $70.7 \%$ of participants of Manhiça-sede and $86.7 \%$ in Ilha Josina (Figure 1). Multi-parallel qPCR detected $77.3 \%$ of analyzed samples Giardia lamblia positive, $5.7 \%$ Cryptosporidium parvum/hominis positive, and $0.7 \%$ Entamoeba histolytica positive (Table 2). We did not observe differences in the proportion of enteric protozoa-infected children between those 
$2-5$ years old and those 5 to 10 years old $(79.2 \%$ and $75.8 \%$, respectively, $p$-value $=0.475)$, neither between HIV-infected or uninfected $(72.2 \%$ and $77.9 \%$, respectively, $p$-value $=0.566)$.

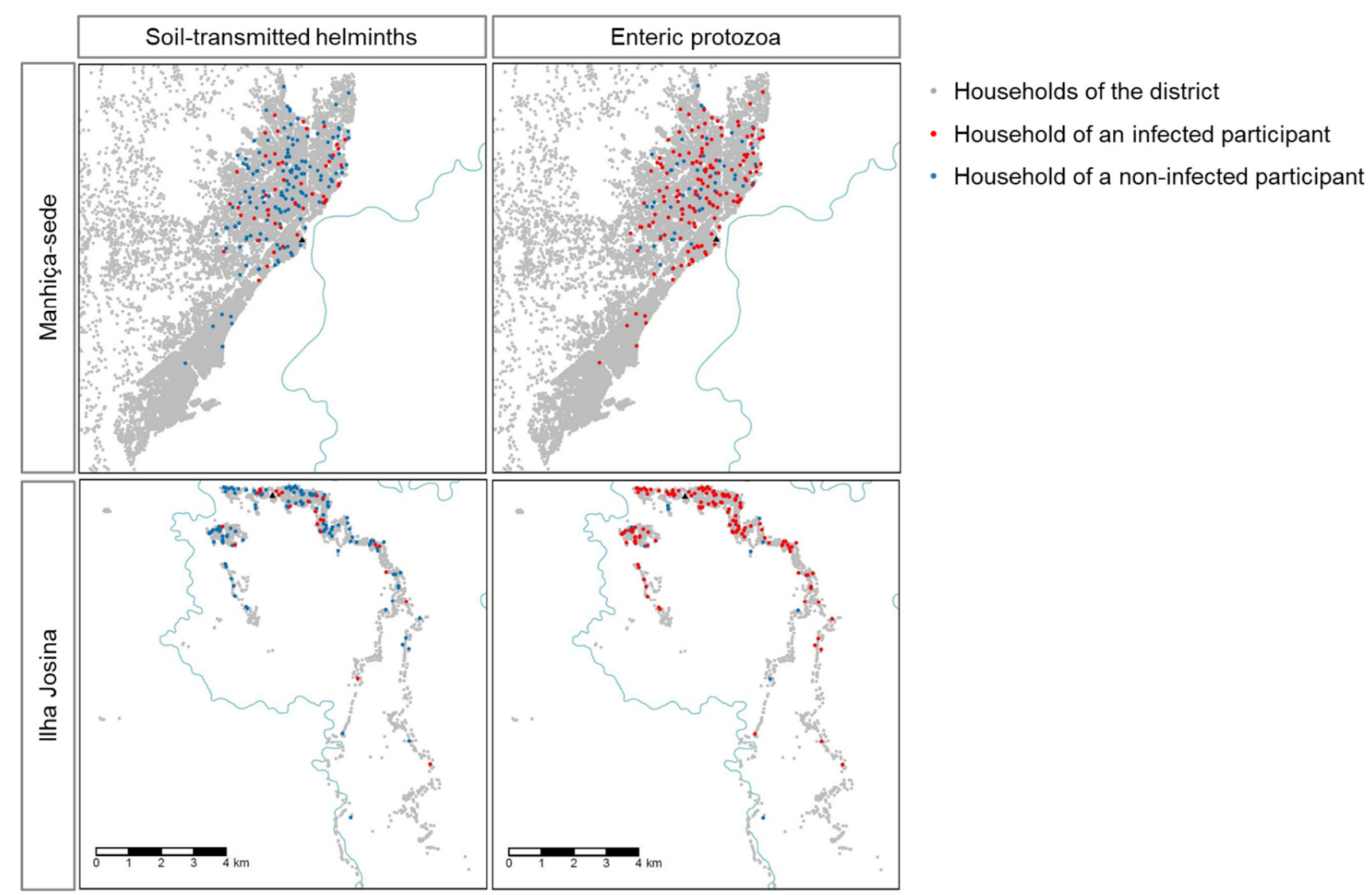

Figure 1. Location of participants infected with at least one soil-transmitted helminth (STH), including Strongyloides stercoralis, or one enteric protozoon. Incomati river is displayed in blue.

\subsection{Polyparasitism}

A proportion of $18.8 \%$ of participants were infected by two or more intestinal parasites (either STH or enteric protozoa), 22.4\% in Manhiça-sede and 13.9\% in Ilha Josina. Sixteen percent of participants had a coinfection between at least one STH and at least one enteric protozoon. G. lamblia and S. stercoralis were the most common coinfection $(7.9 \%)$, followed by G. lamblia and A. lumbricoides (5.7\%). Moreover, three participants were infected by four different intestinal parasites and one participant was infected by five different intestinal parasites (Figure 2).

\subsection{Association Between Household Water and Sanitation Facility Use and STH and Enteric Protozoa Infection}

Children living in a household using protected water well (OR: 2.59, CI: 1.01-6.65, $p$-value $=0.010)$ or unprotected well (OR: 5.21, CI: 1.56-17.46, $p$-value $=0.010)$ displayed a higher odds ratio for infection with at least one protozoon compared to using piped water inside the household after adjusting for participant's age, sex, household latrine type, socioeconomical score, and household distance to the health post. We did not observe any association between household water source and at least one STH, neither between sanitation facility used in the household and at least one STH or at least one protozoon infection (Table 3, Figures S2 and S3). 
A

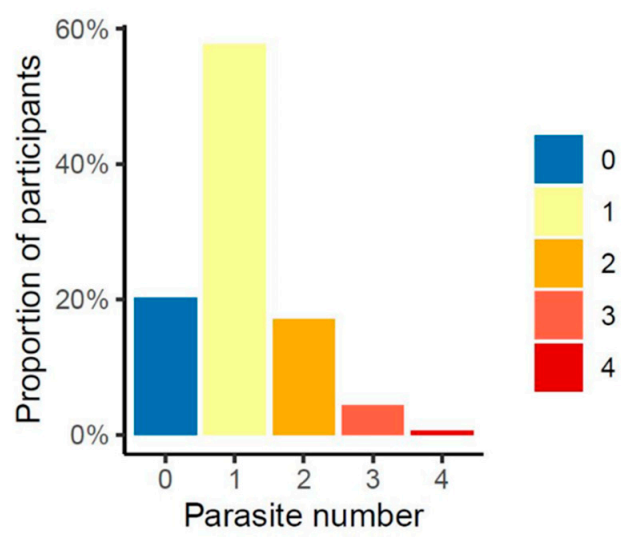

B

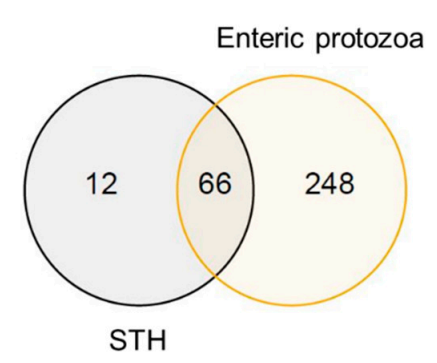

C

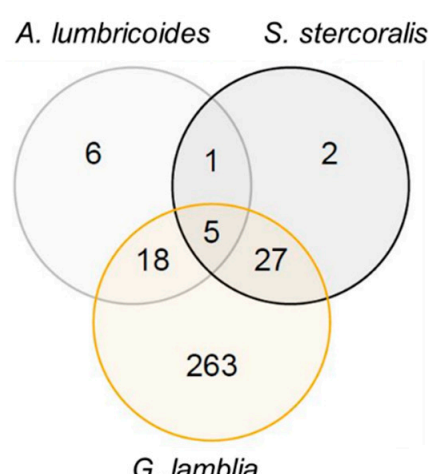

Figure 2. Participants' polyparasitism, (A) proportion of participants per number of intestinal parasites, (B) number of participants with soil-transmitted helminth (STH), including Strongyloides stercoralis, and enteric protozoa coinfection, (C) number of participants coinfected with the most prevalent intestinal parasites in our study: Ascaris lumbricoides, S. stercoralis and Giardia lamblia.

Table 3. Adjusted odds ratio (OR) for being infected by at least one soil-transmitted helminth (STH), including Strongyloides stercoralis, or at least one enteric protozoon per water source or sanitation facility used in the household.

\begin{tabular}{|c|c|c|c|c|}
\hline & \multicolumn{2}{|c|}{ At Least One STH } & \multicolumn{2}{|c|}{$\begin{array}{l}\text { At Least One Enteric } \\
\text { Protozoon }\end{array}$} \\
\hline & $\begin{array}{l}\text { Adjusted OR } \\
(95 \% \mathrm{CI})\end{array}$ & $p$-value & $\begin{array}{l}\text { Adjusted OR } \\
(95 \% \mathrm{CI})\end{array}$ & $p$-value \\
\hline \multicolumn{5}{|l|}{ Water source ${ }^{A}$} \\
\hline $\begin{array}{l}\text { Piped water inside the } \\
\text { household }\end{array}$ & 1.00 & & 1.00 & \\
\hline $\begin{array}{l}\text { Piped water outside the } \\
\text { household }\end{array}$ & $1.09(0.47-2.54)$ & \multirow[t]{5}{*}{0.088} & $1.25(0.58-2.68)$ & \multirow[t]{5}{*}{0.010} \\
\hline Fountain & $1.30(0.35-4.85)$ & & $1.30(0.34-4.94)$ & \\
\hline Protected well & $0.37(0.13-1.09)$ & & $2.59(1.01-6.65)$ & \\
\hline Unprotected well & $0.41(0.13-1.26)$ & & $5.21(1.56-17.46)$ & \\
\hline Other & $1.81(0.34-9.69)$ & & $1.81(0.19-16.97)$ & \\
\hline \multicolumn{5}{|l|}{ Sanitation facility ${ }^{B}$} \\
\hline Toilet connected to septic tank & 1.00 & 0.528 & 1.00 & 0.835 \\
\hline Improved latrine & $0.62(0.23-1.71)$ & & $0.81(0.29-2.26)$ & \\
\hline Unimproved latrine & $0.45(0.14-1.44)$ & 0.528 & $0.62(0.21-1.80)$ & \\
\hline Without latrine & $0.87(0.18-4.21)$ & & $0.86(0.16-4.76)$ & \\
\hline
\end{tabular}

OR: Odds ratio. ${ }^{\mathrm{A}}$ adjusted for age, sex, latrine type, socioeconomical score and distance to the health post. $\mathrm{B}$ adjusted for age, sex, water source type, socioeconomical score and distance to the health post. 


\section{Discussion}

During 2015-2016, we recruited and assessed STH and enteric protozoan infections in 405 children between 2 and 10 years old attending healthcare in Manhiça district, Southern Mozambique. Among them, G. lamblia infection was the most prevalent by far, $77.3 \%$. This is the highest prevalence of giardiasis reported in Mozambique in the past decades.

Certainly, this is a hospital-based cross-sectional study, thus, biases toward sick and symptomatic children. However, a cross-sectional study in Zambezia province, Mozambique, during 2017-2019 observed similar Giardia infection PCR detected prevalences in health centers and in schools in children between 3 and 14 years old $(42 \%$ and $41.7 \%$, respectively) [21]. Moreover, other studies in other Mozambican regions also showed Giardia infection among the most prevalent intestinal parasites. However, their prevalence assessed were lower than in our study. They used techniques with different sensitivity such as ELISA [22-24], and direct microscopy or Ritchie's concentration technique [25]. But, in addition, environmental and socioeconomical conditions can be dissimilar inside the country and prompt different patterns of Giardia contamination [26].

The other enteric protozoa surveilled, Cryptosporidium spp. and E. histolytica, were less prevalent in children attending healthcare in Manhiça district. Regarding Cryptosporidium spp, other hospital-based studies in Mozambique also detected prevalence below $6 \%$ by microscopy or PCR [21,24]. Nonetheless, Cryptosporidium spp. was identified as one of the main causes of moderate to severe diarrhea in children under 5 years old in Manhiça district [19]. Concerning E. histolytica, we only observed $0.7 \%$ of children infected. The Global Enteric Multi-center Study (GEMS) also detected only $0.4 \%$ infection in hospitalized children for diarrhea in Manhiça district in 2007 [27]. Meanwhile, E. histolytica cysts antigens were detected by immunoassays and E. hystolitica/dispar was identified by microscopy in Nampula province [22,24], but other studies using molecular diagnostics did not detect E. histolytica in Zambezia province $[18,20]$. Furthermore, most cross-sectional studies on enteric protozoa infection in the country are in children younger than 5 years old $[19,27]$. In our study, including children older than 5 years old did not seem to determine prevalence of at least one enteric protozoon infection, since children younger than 5 years and older than 5 years old showed similar enteric protozoa infection prevalence.

A proportion of $19.3 \%$ of children were infected by at least one STH, including $S$. stercoralis. Regarding those species formally considered STH by WHO, A. lumbricoides was the most prevalent $(7.4 \%)$, followed by T. trichiura $(4 \%)$, N. americanus $(3 \%)$, and $A$. duodenale $(0.5 \%)$. In fact, S. stercoralis infection was higher $(8.6 \%)$ than any formal STH species. Regarding age, it is understood that older children are not only breastfeeding, they freely move around barefoot and, thus, they can accidentally ingest contaminated food or soil [28]. Our results support that a higher proportion of STH-infected participants were older than 5 years old. This STH infection results are very valuable since last published data on STH infection and on S. stercoralis infection in southern Mozambique were from 2007 and 1995, respectively; before national MDA implementation [17,29,30]. Indeed, we observed less than half the prevalence identified before MDA implementation even though we used a more sensitive diagnostic technique [28,29]. Thus, MDA could have been effective in reducing STH infection in this region.

Nineteen per cent of participants were infected by more than one intestinal parasite and $16 \%$ were infected by a STH and an enteric protozoan. The most common detected co-infections were G. lamblia with S. stercoralis and G. lamblia with A. lumbricoides. Clearly, intestinal parasites infections can have detrimental consequences in children, who are in a physical and intellectual development process. But the synergic impact of coinfection with either multiple STH and/or protozoa in children is still understudied and not well understood [26]. In addition, this study was conducted in an area with high HIV infection in adults with mother-to-child transmission below 5\% [31,32]. While we did not find any statistical difference on intestinal parasite infection regarding HIV infection in our study, Acácio et al. (2018) reported that HIV infection increased the risk of moderate to severe diarrhea caused by Cryptosporidium spp. in children under 5 years old in Manhiça district [33]. 
In this study, we observed a higher odds ratio for enteric protozoa infection when children lived in a household using protected or unprotected water well. This goes in line with other studies $[20,34]$. The three enteric protozoa detected were foodborne and waterborne, they are typically transmitted by ingesting cysts persisting in water. Thus, lack of water quality and quantity and lack of hygiene will facilitate their transmission. Hence, well water could be contaminated from nearby latrines, domestic animals, or other contaminated users. Quantity of water acquired from wells could be insufficient since they involve physical fitness and time for water collection and; these conditions contribute to lack of hygiene [35]. However, Bauhofer et al.'s (2020) study in Mozambique found no association between water use and enteric protozoan infection [22]. Moreover, other studies focusing on water treatment did not find any association either, since cysts can be chlorination resistant $[24,36,37]$. On the other hand, we did not find any association between sanitation and protozoa infection. Thus, water source might be the main Giardia transmission source in this area.

Concerning STH, we did not observe any association with water and sanitation use. Other studies point that other unaccounted factors could be playing a role, such as soil conditions, household density, latrine sharing, latrine cleanliness, washing hands with soap, or school WASH conditions [26,29]. In addition, zoonotic infections could be also occurring [34].

This study has some limitations. First, we are reporting healthcare children prevalence, and community prevalence could differ. Second, we collected one stool sample per participant. Eggs, larvae, and cysts release in feces is intermittent, thus, prevalence could still be underestimated [14]. Third, not all participants were tested for all parasites. DNA extraction and multi-parallel PCR reagents were shipped from Houston, Texas, and CISM lab personnel were trained to perform multi-parallel qPCR in Mozambique. Damage of sensitive reagents due to suboptimal international shipment handling prevented us from performing qPCR in all intended samples. Fourth, qPCR has been discussed to detect other parasite specimens than the eggs or the cysts. Thus, this could affect qPCR specificity [38]. Moreover, this study was completed prior to the universal use of an exogenous internal control. Although and internal control was absent from this study, the DNA extraction method used has previously shown high fidelity with low inhibition. Fifth, hygiene, environmental, school and water and sanitation infrastructure operability and accessibility data were not available. This may have failed to capture WASH-related factors that could also be contributing to intestinal parasites transmission.

However, the main strength of this study is that all intestinal parasites were identified by a highly sensitive and specific diagnostic technique on site-multi-parallel qPCR. This technique is less sensitive to stool texture and freshness than direct microscopy or KatoKatz and allowed us to differentiate pathogenic from nonpathogenic parasites (e.g., E. histolytica, E. dispar) [39].

STH are mainly controlled through MDA with anthelmintics to population at risk. Nevertheless, MDA does not prevent from reinfection and researchers are uncovering anthelmintic resistance emergence [40]. The official inclusion of WASH improvements in STH national control programs could contribute to reduce STH reinfection and to achieve STH elimination as a public health problem [41]. In addition, WASH improvement is a longterm strategy that could prevent from other WASH related pathogens, such as S. stercoralis or enteric protozoa and, furthermore, it would enhance population living conditions.

\section{Materials and Methods}

\subsection{Study Area}

The study was carried out in Manhiça district, in Southern Mozambique, during August 2015 and December 2016 in the context of EcoHeMa study. Recruitment was conducted in two areas: Manhiça-sede, a peri-urban area of 78,479 inhabitants, and Ilha Josina, a rural area of 8288 inhabitants. (Figure S1) The climate is subtropical with a warm and rainy season (November to April) and a cool and dry season (June to October). 
The average annual temperatures oscillate from $22{ }^{\circ} \mathrm{C}$ to $24{ }^{\circ} \mathrm{C}$ and the average annual precipitation from $600 \mathrm{~mm}$ to $1000 \mathrm{~mm}$.

Since 1996, the Manhiça Health Research Centre (Centro de Investigação em Saúde de Manhiça, CISM) runs a Demographic Surveillance System (DSS) covering the entire district (201,845 inhabitants). Every district household is geolocalized and every resident has a permanent identification number (PermID) issued by the DSS. The demographic trends in Manhiça District have been described in detail elsewhere [42].

Manhiça district followed expansive population pyramid distribution [42]. Houses are simple, with walls typically made of cane and concrete blocks, covered by zinc plates. The main occupations are farming, petty trading, and employment on a large sugar cane estate. The overall community prevalence of HIV / AIDS in the district was $40 \%$ [42].

\subsection{Study Population}

This study was a nested study inside EcoHeMa study, which aims to determine the prevalence of co-infection between P. falciparum malaria and helminthiasis at the hospital level. Recruitment was conducted in Manhiça-sede District Hospital and Ilha Josina Health center. (Figure S1) We included children aged between 2 and 10 years old, resident in the DSS area, presenting themselves at the study health centers and that their guardians gave informed consent. We excluded all children having received anthelmintics and/or antimalarial in the last 30 days.

In the absence of updated data, a conservative STH prevalence of $50 \%$ will ensure a sample size enough to achieve a precision of $5 \%$ in the estimation of the $95 \%$ CIs regardless of the true prevalence. Thus, an estimated sample size of 384 participants allowed us to answer our question. We enrolled 405 children DSS resident between 2-10 years old visiting a study health center, including those that were finally hospital admitted.

\subsection{Study Design}

It was a cross-sectional study. After child adult guardian inform consent, a clinical study member explained sample collection methodology to the participants and provided a feces collection kit. The kit consisted of one sterile flask of $50 \mathrm{~mL}$ for stool sampling and three pairs of surgical gloves for protection. The field worker collected the stool sample the following morning after recruitment at participants' households. In case stool samples could not be delivered that day, the field worker came back to the household until five consecutive days. Samples of hospital admitted participants were collected at the hospital (Figure 3).

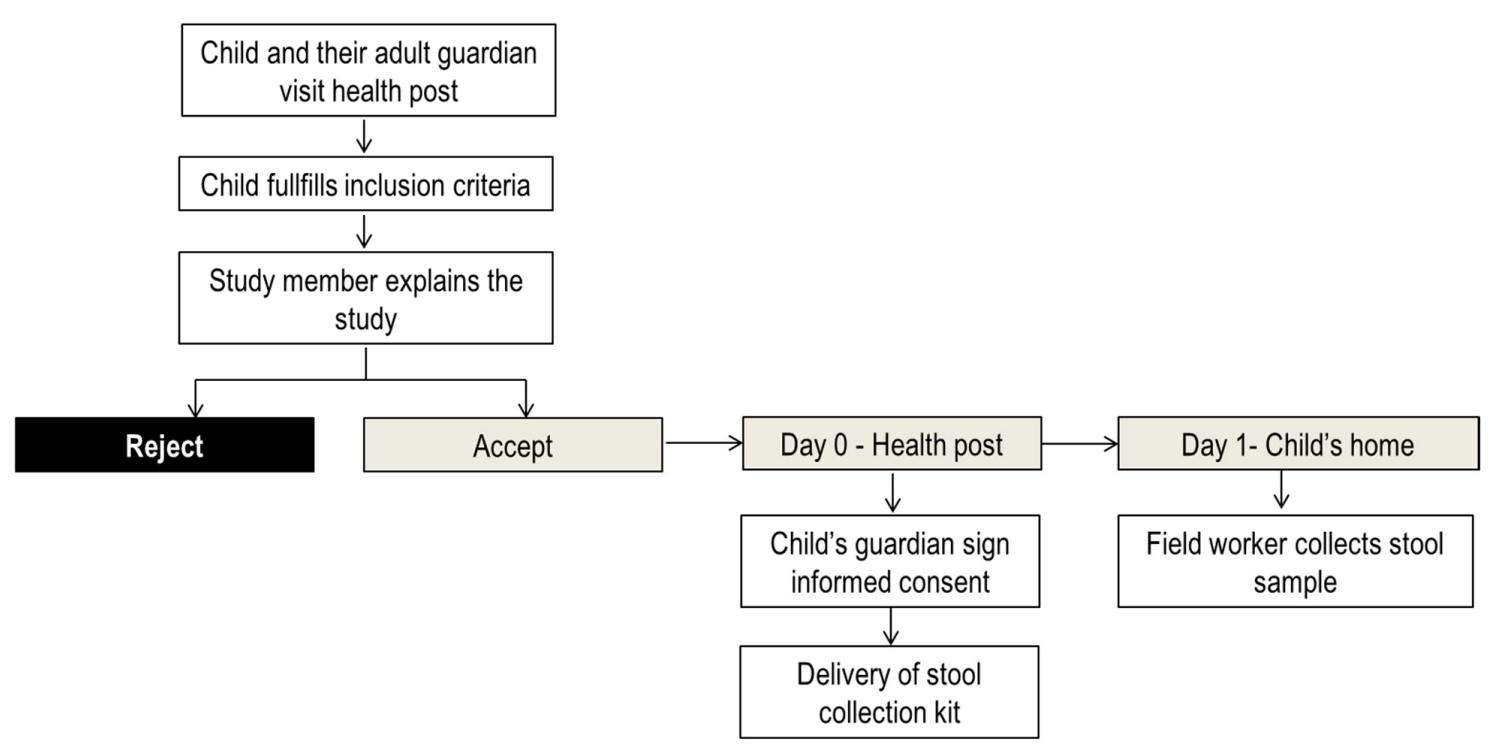

Figure 3. Stool sample collection flow diagram. 


\subsection{Sample Examination}

After collection stool samples were refrigerated at $+/-4{ }^{\circ} \mathrm{C}$ in cool boxes containing cold packs and transported to the laboratory within $8 \mathrm{~h}$. Stool samples were stored at $-80{ }^{\circ} \mathrm{C}$ and processed in CISM laboratory. Participant samples were thawed and analyzed for molecular diagnosis by a multi-parallel quantitative real-time qPCR technique [39] in duplicate. DNA was extracted from $50 \mathrm{mg}$ stool by using the MP FastDNA for Soil Kit (MP Biochemicals, Solon, OH, USA) according to manufacturer's instructions [43]. Briefly, positives were determined based on the dynamic range of a standard set of specific parasite sequences. A sample was considered negative if the cycle threshold was $(\mathrm{Ct})>38$ based on the limit of detection to parasite DNA sequences. Species-specific primers and FAM-labeled MGB probes were selected (Applied Biosystems, Forest City, CA, USA) for each of the 8 parasites (Table S1). Primer/probes were designed using Primer Express Software v3.0.1 (Applied Biosystems). Every reaction was performed in a total volume of $7 \mu \mathrm{L}$ containing $3.5 \mu \mathrm{L}$ Taqman ${ }^{\mathrm{TM}}$ fast mix (Applied Biosystems, Forest City, CA, USA), $2 \mu \mathrm{L}$ template DNA, and $1.5 \mu \mathrm{L}$ of species-specific primers ( $900 \mathrm{nM}$ final concentration) and FAM-labeled MGB probes (100 $\mu \mathrm{M}$ final concentration). All unknown samples were performed in duplicate. DNA extraction and qPCR technique procedures are described elsewhere [39].

\subsection{Participants Data}

Participant demographic and household geolocation and characteristics were obtained from CISM DSS. Participants' HIV status was determined by rapid test; HIV test (Abbott Laboratories, North Chicago, IL, USA) and Uni-Gold HIV test (Trinity Biotech, Bray, Ireland).

Water and sanitation facilities were defined according to the WHO/UNICEF Joint Monitoring Program [44]. Household water sources were classified as: piped water inside the household, piped water outside the household (in the backyard), fountain, protected well (with a cover and an elevated platform), unprotected well (without a cover and/or an elevated platform), and other water sources. Household sanitation facilities were classified as: toilet connected to a septic tank, improved latrine (latrine with a tank isolating the feces from the environment), unimproved latrine (without a tank that protect the feces from the environment), or without a latrine.

A socioeconomical wealth index was created to attribute a household socioeconomic score (SES) to each household of Manhiça district. It was based on household characteristics and assets possession collected during CISM DSS. A multiple correspondence analysis (MCA) with 17 characteristics was conducted to determine the weights of every characteristic or asset [45]. We excluded water and sanitation variables to avoid over adjustment. Manhiça district household SES was then divided in tertiles to classify households in poor SES status, middle SES, and rich SES.

\subsection{Data Analysis}

Participant population and STH and protozoan infections were described using absolute and relative frequency. Categorical variables were expressed as absolute frequency and percentage and they were compared with Fisher's exact test.

We estimated the odds ratio for infection with at least one STH infection or infection with at least one enteric protozoon. Although S. stercoralis is not formally considered a STH by WHO we included it in the STH group for this analysis. We fitted a logistic regression model. The models were selected using backward procedure. For water source explanatory variable, we adjusted our estimations for age, sex, latrine type, socioeconomical score, and distance to the health post (Euclidean distance); and for sanitation facility, we adjusted our estimations for age, sex, water source type, socioeconomical score, and distance to the health post. Our references were piped water inside the household and toilet connected to a septic tank. 
We performed statistical analysis and data management and visualization using STATA 16 (StataCorp., College Station, TX, USA) and R Statistical Software Version 3.5.3 [46].

\subsection{Ethics}

The study protocol was reviewed and approved by the National Bioethics Committee for Health in Mozambique (reference: IRB00002657) and by Baylor College of Medicine (H-38221). All child adult guardians signed the informed consent in their choice of language (Portuguese or Changana). In case of illiterate adult guardians, study explanation and inform consent process was conducted in the presence of an independent witness and child guardians put a finger print. Infected participants were treated following the national guidelines.

Supplementary Materials: The following are available online at https:/ /www.mdpi.com/article/10 .3390/pathogens10070838/s1. Figure S1: Location of Manhiça-sede and Ilha Josina health centers and location of household study participants. Figure S2: Proportion of participants with soil-transmitted helminth infection per (A) gender, (B) age, (C) socioeconomical status (SES), (D) water source type and (E) sanitation facility type. Figure S3: Proportion of participants with enteric protozoa infection per (A) gender, (B) age, (C) socioeconomical status (SES), (D) water source type and (E) sanitation facility type. Table S1: Species-specific primers used in multi-parallel real-time quantitative qPCR selected for each of the 8 parasites.

Author Contributions: Conceptualization: B.G.-P., I.C., C.J., C.D., A.N., R.M. and J.M.; methodology: B.G.-P., A.N., R.M. and J.M.; software: B.G.-P., I.C. and R.M.; validation: R.M.; formal analysis: B.G.-P. and R.M.; investigation: B.G.-P., I.C. and A.N.; resources: C.J., C.D., A.N., A.C., C.S., R.M. and J.M.; data curation: B.G.-P., I.C. and R.M.; writing-original draft preparation: B.G.-P.; writing-review and editing: B.G.-P., I.C., C.J., A.C., J.D.S., C.S., C.D., A.N., R.M. and J.M.; visualization: B.G.-P.; supervision: C.D., A.N., R.M. and J.M.; project administration: B.G.-P., I.C. and A.N.; funding acquisition: A.N., C.D. and J.M. All authors have read and agreed to the published version of the manuscript.

Funding: The study was funded by the Fundo Nacional de Investigação (FNI) which is a public institution created by the Government of Mozambique. This work was also supported by Mundo Sano Foundation (www.mundosano.org), Jose Muñoz was the Principal Investigator of the study. We acknowledge support from the Spanish Ministry of Science and Innovation through the" Centro de Excelencia Severo Ochoa 2019-2023" Program (CEX2018-000806-S), and support from the "Generalitat de Catalunya" through the CERCA Program. CISM is supported by the Government of Mozambique and the Spanish Agency for International Development (AECID). The multi-parallel real-time quantitative PCR was supported by the section of Pediatric Tropical Medicine, National School of Tropical Medicine, Baylor College of Medicine. The funders had no role in study design, data collection, analysis, interpretation of data, decision to publish, or preparation of the manuscript.

Institutional Review Board Statement: The DSS data collection has ethical approval from the Institutional Ethics Review Board for Health at CISM (approval no. CIBS_CISM/01/12), from the National Bioethics Committee for Health (approval no. 174/CNBS/ 12) and the Institutional Review Board for Human Subject Research Baylor College of Medicine (H-38221). The study was performed according to the Declaration of Helsinki (version of Fortaleza, Brazil, October 2013), current ICH-GCP guidelines and all applicable national and local regulatory requirements (Spanish Royal Decree 1090/2015). DSS included participants gave informed consent.

Informed Consent Statement: Written informed consent was obtained from all subjects involved in the study.

Data Availability Statement: The data underlying this article will be shared on reasonable request to the corresponding author. 
Acknowledgments: We would like to thank Manhiça District Hospital and Ilha Josina health center personnel and CISM lab technicians that contributed to this study. We would also like to acknowledge all CISM field-supervisors, field-workers and data managers that contributed with DSS data collection and curation. We particularly would like to thank Osvaldo Muchisse for his contribution on database cleaning.

Conflicts of Interest: RM reports research funding from Romark Laboratories, L.C., but did not involve this project. The other authors declare no conflict of interest. The sponsors had no role in the design, execution, interpretation, or writing of the study.

\section{References}

1. Berkman, D.S.; Lescano, A.G.; Gilman, R.H.; Lopez, S.L.; Black, M.M. Effects of stunting, diarrhoeal disease, and parasitic infection during infancy on cognition in late childhood: A follow-up study. Lancet 2002, 359, 564-571. [CrossRef]

2. WHO. Soil-Transmitted Helminth Infections Fact. Sheet; World Health Organization: Geneva, Switzerland, 2019.

3. Squire, S.A.; Ryan, U. Cryptosporidium and Giardia in Africa: Current and future challenges. Parasites Vectors 2017, 10, 195. [CrossRef]

4. WHO. Ending the Neglect to Attain the Sustainable Development Goals: A Road Map for Neglected Tropical Diseases 2021-2030; World Health Organization: Geneva, Switzerland, 2020.

5. Okoyo, C.; Nikolay, B.; Kihara, J.; Simiyu, E.; Garn, J.V.; Freeman, M.C.; Mwanje, M.T.; Mukoko, D.A.; Brooker, S.J.; Pullan, R.L.; et al. Monitoring the impact of a national school based deworming programme on soil-transmitted helminths in Kenya: The first three years, 2012-2014. Parasites Vectors 2016, 9, 408. [CrossRef]

6. Ortu, G.; Assoum, M.; Wittmann, U.; Knowles, S.; Clements, M.; Ndayishimiye, O.; Basáñez, M.-G.; Lau, C.; Clements, A.; Fenwick, A.; et al. The impact of an 8-year mass drug administration programme on prevalence, intensity and co-infections of soil-transmitted helminthiases in Burundi. Parasites Vectors 2016, 9, 513. [CrossRef] [PubMed]

7. Tun, A.; Myat, S.M.; Gabrielli, A.F.; Montresor, A. Control of soil-transmitted helminthiasis in Myanmar: Results of 7 years of deworming. Tropical medicine \& international health. Trop. Med. Int. Health 2013, 18, 1017-1020.

8. Montresor, A.; Mupfasoni, D.; Mikhailov, A.; Mwinzi, P.; Lucianez, A.; Jamsheed, M.; Gasimov, E.; Warusavithana, S.; Yajima, A.; Bisoffi, Z.; et al. The global progress of soil-transmitted helminthiases control in 2020 and World Health Organization targets for 2030. PLoS Negl. Trop. Dis. 2020, 14, e0008505. [CrossRef]

9. Savioli, L.; Smith, H.; Thompson, A. Giardia and Cryptosporidium join the 'Neglected Diseases Initiative'. Trends Parasitol. 2006, 22, 203-208. [CrossRef]

10. Dacal, E.; Saugar, J.M.; de Lucio, A.; Hernández-de-Mingo, M.; Robinson, E.; Köster, P.C.; Aznar-Ruiz-de-Alegría, M.L.; Espasa, M.; Ninda, A.; Gandasegui, J.; et al. Prevalence and molecular characterization of Strongyloides stercoralis, Giardia duodenalis, Cryptosporidium spp., and Blastocystis spp. isolates in school children in Cubal, Western Angola. Parasites Vectors $2018,11,67$. [CrossRef] [PubMed]

11. Buonfrate, D.; Bisanzio, D.; Giorli, G.; Odermatt, P.; Fürst, T.; Greenaway, C.; French, M.; Reithinger, R.; Gobbi, F.; Montreso, A.; et al. The Global Prevalence of Strongyloides stercoralis Infection. Pathogens 2020, 9, 468. [CrossRef]

12. Fleitas, P.E.; Travacio, M.; Martí-Soler, H.; Socías, M.E.; Lopez, W.R.; Krolewiecki, A.J. The Strongyloides stercoralis-hookworms association as a path to the estimation of the global burden of strongyloidiasis: A systematic review. PLoS Negl. Trop. Dis. 2020, 14, e0008184. [CrossRef] [PubMed]

13. Torgerson, P.R.; Devleesschauwer, B.; Praet, N.; Speybroeck, N.; Willingham, A.L.; Kasuga, F.; Rokni, M.B.; Zhou, X.-N.; Fèvre, E.M.; Sripa, B.; et al. World Health Organization Estimates of the Global and Regional Disease Burden of 11 Foodborne Parasitic Diseases, 2010: A Data Synthesis. PLoS Med. 2015, 12, e1001920. [CrossRef] [PubMed]

14. Krolewiecki, A.J.; Lammie, P.; Jacobson, J.; Gabrielli, A.F.; Levecke, B.; Socias, E.; Arias, L.M.; Sosa, N.; Abraham, D.; Cimino, R.; et al. A public health response against Strongyloides stercoralis: Time to look at soil-transmitted helminthiasis in full. PLoS Negl. Trop. Dis. 2013, 7, e2165. [CrossRef]

15. Nikolay, B.; Brooker, S.J.; Pullan, R.L. Sensitivity of diagnostic tests for human soil-transmitted helminth infections: A metaanalysis in the absence of a true gold standard. Int. J. Parasitol. 2014, 44, 765-774. [CrossRef]

16. WHO. World Health Organization and UNICEF Join Monitoring Programme for Water Supply. Estimates on the use of water, sanitation and hygiene in Mozambique. 2017.

17. Grau-Pujol, B.; Massangaie, M.; Cano, J.; Maroto, C.; Ndeve, A.; Saute, F.; Muñoz, J. Frequency and distribution of neglected tropical diseases in Mozambique: A systematic review. Infect. Dis. Poverty 2019, 8, 103. [CrossRef] [PubMed]

18. Gutiérrez, M.J.I.; Mingo, M.H.; Lucio, A.; Gil, H.; Morales, L.; Seguí, R.; Nacarapad, E.; Antolía, C.M.; LlinareseJosé, F.J.B.; Esteban, G.; et al. Association between enteric protozoan parasites and gastrointestinal illness among HIV- and tuberculosis-infected individuals in the Chowke district, southern Mozambique. Acta Trop. 2017, 170, 197-203. [CrossRef] [PubMed]

19. Nhampossa, T.; Mandomando, I.; Acacio, S.; Quintó, L.; Vubil, D.; Ruiz, J.; Nhalungo, D.; Sacoor, C.; Nhabanga, A.; Nhacolo, A.; et al. Diarrheal Disease in Rural Mozambique: Burden, Risk Factors and Etiology of Diarrheal Disease among Children Aged 0-59 Months Seeking Care at Health Facilities. PLoS ONE 2015, 10, e0119824. [CrossRef] 
20. Muadica, A.S.; Balasegaram, S.; Beebeejaun, K.; Köster, P.C.; Bailo, B.; Hernández-De-Mingo, M.; Dashti, A.; Dacal, E.; Saugar, J.M.; Fuentes, I.; et al. Risk associations for intestinal parasites in symptomatic and asymptomatic schoolchildren in central Mozambique. Clin. Microbiol. Infect. 2021, 27, 624-629. [CrossRef] [PubMed]

21. Muadica, A.; Köster, P.; Dashti, A.; Bailo, B.; Hernández-De-Mingo, M.; Balasegaram, S.; Carmena, D. Molecular Diversity of Giardia duodenalis, Cryptosporidium spp., and Blastocystis sp. in Symptomatic and Asymptomatic Schoolchildren in Zambézia Province (Mozambique). Pathogens 2021, 10, 255. [CrossRef] [PubMed]

22. Bauhofer, A.F.L.; Cossa-Moiane, I.; Marques, S.; Guimarães, E.L.; Munlela, B.; Anapakala, E.; Chilaúle, J.J.; Cassocera, M.; Langa, J.S.; Chissaque, A.; et al. Intestinal protozoan infections among children 0-168 months with diarrhea in Mozambique: June 2014-January 2018. PLoS Negl. Trop. Dis. 2020, 14, e0008195. [CrossRef]

23. Bauhofer, A.F.L.; Cossa-Moiane, I.L.C.; Marques, S.D.A.; Guimarães, E.; Munlela, B.A.; Anapakala, E.M.; Chiláule, J.J.; Cassocera, M.; Langa, J.S.; Chissaque, A.; et al. Intestinal protozoa in hospitalized under-five children with diarrhoea in Nampula-A cross-sectional analysis in a low-income setting in northern Mozambique. BMC Infect. Dis. 2021, 21, 201. [CrossRef]

24. Ferreira, F.S.; Pereira, F.; Martins, M. Intestinal parasitic infections in children under five in the Central Hospital of Nampula, Northern Mozambique. J. Infect. Dev. Ctries. 2020, 14, 532-539. [CrossRef] [PubMed]

25. Fonseca, A.M.; Fernandes, N.; Ferreira, F.S.; Gomes, J.; Centeno-Lima, S. Intestinal parasites in children hospitalized at the Central Hospital in Maputo, Mozambique. J. Infect. Dev. Ctries. 2014, 8, 786-789. [CrossRef]

26. Harhay, M.O.; Horton, J.; Olliaro, P.L. Epidemiology and control of human gastrointestinal parasites in children. Expert Rev. Anti-Infect. Ther. 2010, 8, 219-234. [CrossRef]

27. Mandomando, I.M.; Alonso, P.L.; Macete, E.V.; Gascon, J.; Ruiz, J.; Sacarlal, J.; Sanz, S.; Navia, M.M.; Abacassamo, F.; Vila, J.; et al. Etiology of diarrhea in children younger than 5 years of age admitted in a rural hospital of southern Mozambique. Am. J. Trop. Med. Hyg. 2007, 76, 522-527. [CrossRef]

28. Meurs, L.; Polderman, A.M.; Melchers, N.V.S.V.; Brienen, E.A.T.; Verweij, J.J.; Groosjohan, B.; Mendes, F.; Mechendura, M.; Hepp, D.H.; Langenberg, M.C.C.; et al. Diagnosing Polyparasitism in a High-Prevalence Setting in Beira, Mozambique: Detection of Intestinal Parasites in Fecal Samples by Microscopy and Real-Time PCR. PLoS Negl. Trop. Dis. 2017, 11, e0005310. [CrossRef]

29. Augusto, G.; Nalá, R.; Casmo, V.; Sabonete, A.; Mapaco, L.; Monteiro, J. Geographic distribution and prevalence of schistosomiasis and soil-transmitted helminths among schoolchildren in Mozambique. Am. J. Trop. Med. Hyg. 2009, 81, 799-803. [CrossRef]

30. Enosse, S.M.; Gama Vaz, R.; Schwalbach, J. Ancylostomiase duodenale e vesicais no vale do Infulene e Mahotas, Maputo. Rev. Med. Mocamb. 1995, 6, 103.

31. González, R.; Munguambe, K.; Aponte, J.; Bavo, C.; Nhalungo, D.; Macete, E.; Alonso, P.L.; Menéndez, C.; Naniche, D. High HIV prevalence in a southern semi-rural area of Mozambique: A community-based survey. HIV Med. 2012, 13, 581-588. [CrossRef] [PubMed]

32. Fuente-Soro, L.; Fernández-Luis, S.; López-Varela, E.; Augusto, O.; Nhampossa, T.; Nhacolo, A.; Bernardo, E.; Burgueño, B.; Ngeno, B.; Couto, A.; et al. Community-based progress indicators for prevention of mother-to-child transmission and mortality rates in HIV-exposed children in rural Mozambique. BMC Public Health 2021, 21, 520.

33. Acácio, S.; Nhampossa, T.; Quintó, L.; Vubil, D.; Sacoor, C.; Kotloff, K.; Farag, T.; Dilruba, N.; Macete, E.; Levine, M.M.; et al. The role of HIV infection in the etiology and epidemiology of diarrheal disease among children aged 0-59 months in Manhiça District, Rural Mozambique. Int. J. Infect. Dis. 2018, 73, 10-17. [CrossRef] [PubMed]

34. Aiemjoy, K.; Gebresillasie, S.; Stoller, N.E.; Shiferaw, A.; Tadesse, Z.; Chanyalew, M.; Aragie, S.; Callahan, K.; Keenan, J.D. Epidemiology of Soil-Transmitted Helminth and Intestinal Protozoan Infections in Preschool-Aged Children in the Amhara Region of Ethiopia. Am. J. Trop. Med. Hyg. 2017, 96, 866-872. [CrossRef] [PubMed]

35. Cairncross, S.; Bartram, J.; Cumming, O.; Brocklehurst, C. Hygiene, sanitation, and water: What needs to be done? PLoS Med. 2010, 7, e1000365. [CrossRef]

36. Di Benedetto, M.A.; Di Piazza, F.; Maida, C.M.; Firenze, A.; Oliveri, R. Occurrence of Giardia and Cryptosporidium in wastewater, surface water and ground water samples in Palermo (Sicily). Ann. Ig. Med. Prev. Comunita 2005, 17, 367-375.

37. Pickering, A.J.; Njenga, S.M.; Steinbaum, L.; Swarthout, J.; Lin, A.; Arnold, B.F.; Stewart, C.P.; Dentz, H.N.; Mureithi, M.; Chieng, B.; et al. Effects of single and integrated water, sanitation, handwashing, and nutrition interventions on child soil-transmitted helminth and Giardia infections: A cluster-randomized controlled trial in rural Kenya. PLoS Med. 2019, 16, e1002841. [CrossRef] [PubMed]

38. Papaiakovou, M.; Gasser, R.B.; Littlewood, D.T.J. Quantitative PCR-Based Diagnosis of Soil-Transmitted Helminth Infections: Faecal or Fickle? Trends Parasitol. 2019, 35, 491-500. [CrossRef]

39. Mejia, R.; Vicuña, Y.; Vaca, M.; Cooper, P.J.; Chico, M.; Nutman, T.B.; Broncano, N.; Sandoval, C. A novel, multi-parallel, real-time polymerase chain reaction approach for eight gastrointestinal parasites provides improved diagnostic capabilities to resource-limited at-risk populations. Am. J. Trop. Med. Hyg. 2013, 88, 1041-1047. [CrossRef] [PubMed]

40. Moser, W.; Schindler, C.; Keiser, J. Efficacy of recommended drugs against soil transmitted helminths: Systematic review and network meta-analysis. BMJ 2017, 358, j4307. [CrossRef]

41. Freeman, M.C.; Clasen, T.; Brooker, S.J.; Akoko, D.O.; Rheingans, R. The impact of a school-based hygiene, water quality and sanitation intervention on soil-transmitted helminth reinfection: A cluster-randomized trial. Am. J. Trop. Med. Hyg. 2013, 89, 875-883. [CrossRef] 
42. Nhacolo, A.; Jamisse, E.; Augusto, O.; Matsena, T.; Hunguana, A.; Mandomando, I.; Arnaldo, C.; Munguambe, K.; Macete, E.; Alonso, P.; et al. Cohort profile update: Manhiça health and demographic surveillance system (HDSS) of the Manhiça health research centre (CISM). Int. J. Epidemiol. 2021, 50, 395. [CrossRef]

43. da Silva, A.J.; Bornay-Llinares, F.J.; Moura, I.N.; Slemenda, S.B.; Tuttle, J.L.; Pieniazek, N.J. Fast and reliable extraction of protozoan parasite DNA from fecal specimens. Mol. Diagn. 1999, 4, 57-64. [CrossRef]

44. JMP. WASH Data Monitoring Methods: Joint Monitoring Programme WHO/UNICEF. 2018. Available online: https://washdata. org/monitoring/methods (accessed on 15 May 2021).

45. Ayele, D.; Zewotir, T.; Mwambi, H. Multiple correspondence analysis as a tool for analysis of large health surveys in African settings. Afr. Health Sci. 2014, 14, 1036-1045. [CrossRef] [PubMed]

46. R Core Team. R: A Language and Environment for Statistical Computing; R Foundation for Statistical Computing: Vienna, Austria, 2019; Available online: https: / / www.R-project.org/ (accessed on 15 June 2021). 